\title{
Optimizing the Supply Chain in a Fuel Process Industry
}

\author{
Amit Agrawal ${ }^{1}$ \\ ${ }^{1}$ Assistant Professor, Institute of Business Management, GLA University, Mathura, India. \\ E-mail: amit.agrawal@gla.ac.in
}

Article History: Received: 11 January 2021; Accepted: 27 February 2021; Published online: 5 April 2021

\begin{abstract}
The Supply Chain Improvement (SCO) project is being introduced by KNPC, which recognises the major business advantages of improved hydrocarbon supply chain efficiency. The objectives of this work is to strengthen, optimise, and integrate supply scheduling and processes not just at stage of enterprise, but also throughout the entire KNPC framework. This is expected to lead to an improvement in the company's bottom line and facilitate the management of business operations at the highest level of efficiency, agility and profitability. In ever changing market conditions and globally competitiveness, it is necessary that raw material supply storage and product delivery were carried out at the lowest possible time and efficiency. Otherwise export oriented refinery like KNPC cannot remain in business with profit. KNPC has therefore embarked on ambitious multi-year operational excellence programs aimed at enhancing its operations and business processes that include short / mid-term planning, scheduling, accounting for growth, inventory management, and performance management. The aim is to achieve top-quartile financial results by accessing new value streams, encapsulating business processes of best practice and motivating employees of businesses to work in a collaborative atmosphere within the global and cross-functional business cycle to make smarter, quicker and more competitive choices.
\end{abstract}

\section{Keywords: Supply Chain, Optimization, Business Cycle.}

\section{Introduction}

The key raw material for the refinery is oil. LPG, mogas, naphtha, kerosene ATK, gas oil and fuel oil are the finished products of the refinery. Raw materials and the cost of goods are unpredictable. Based on their consistency, many of the petroleum products can be blended to some degree to satisfy consumer requirements. This gives excellent optimization space[1-4].Further, petroleum product and feed are to be moved seamlessly to utilize the market demand and its price.

Petroleum refining industry is rethinking the method of conducting business both externally and internally utilizing modern optimization techniques [5]. Supply Chain Optimization (SCO) is a business process which has promoted significantly from advances in optimization software and solutions. SCO's primary goal is to enhance turnover by integrating Crude Supply management and transactional flows inside a company, and to vendor and stakeholder organizations [6-8]. A distinctive petroleum refining company's supply chain includes a big range of processes, beginning with purchase of crude, transportation to company, refining operations, product blending, transportation of products and ultimately supplying the product to users [9-12]. The quality of the value network process for the correct crude oil is not only linked to transport expenditure included in delivering it to the refinery, but it should also take into account the requirement to manage the active behavior of the entire refinery network in various situations, the abilities and limitations of changing the crude into products in a refinery [1315]. Many of the productions and related constraints can be deterministic, but prices are stochastic in nature and increasingly environmental legislation of various countries further adds to need dimension as well as the product volume [16].

Huge amount of operational data and decision making at various levels are part of the process. Such conditions involve extensive preparation for a specified tenure-usually for a year. Often the production tactics are further divided into practicable procedures with comprehensive plan of every occurrence and incident in the refining procedures over time [17]. Depending on the availability and ambiguity of details, the scheduling horizons range from a few days to weeks, and decisions are taken hourly [20-23].

The refining industry extends well over half a century, using mathematical techniques but limited to minorglitches that could be resolved manually, such as gasoline blending.

The use of LP has been expanded to a variety of grass-root design and configuration, principal investment research, preparation of a variety of projects, supply and circulation plans. The restrictions to progress are the size of the matrix, the computer's ability or the time it takes to find a solution or both, and the exactness of the outcomes of LP that depends on the rationality of input data [18]. Therefore, refinery planners have resolved complicated refinery planning issues by dividing it into sub-problems and this is present in the way in which some refineries work their planning, upstream operations, central engineering, refining, supply and transport. Generally, the issue of refinery scheduling is broken down into three sub-problems-oil production, refining and blending, and delivery of the commodity [19-23]. 
SCO focuses on enhancing its business processes that include short / mid-term planning, scheduling, output accounting, inventory management, and performance administration[24, 25]. It is expected that SCO can achieve profitability of about 35 cents / bbl of crude.

\section{Scenario of Current Market}

The total gross margin of the refinery is the difference between the sales price of goods and the purchasing price of oil and is generally referred to as the cracking spread[26]. It can be understood from the following graph that the margin is very unpredictable, as seen in figure 1.It is about 4 to 6 dollar per barrel.It further changes depending on the crude processed and refinery location. Supply chain management will help in achieving the additional margin by moving the product to regions where there is demand and able to select the crude which is most suitable for the given refinery configuration [27].

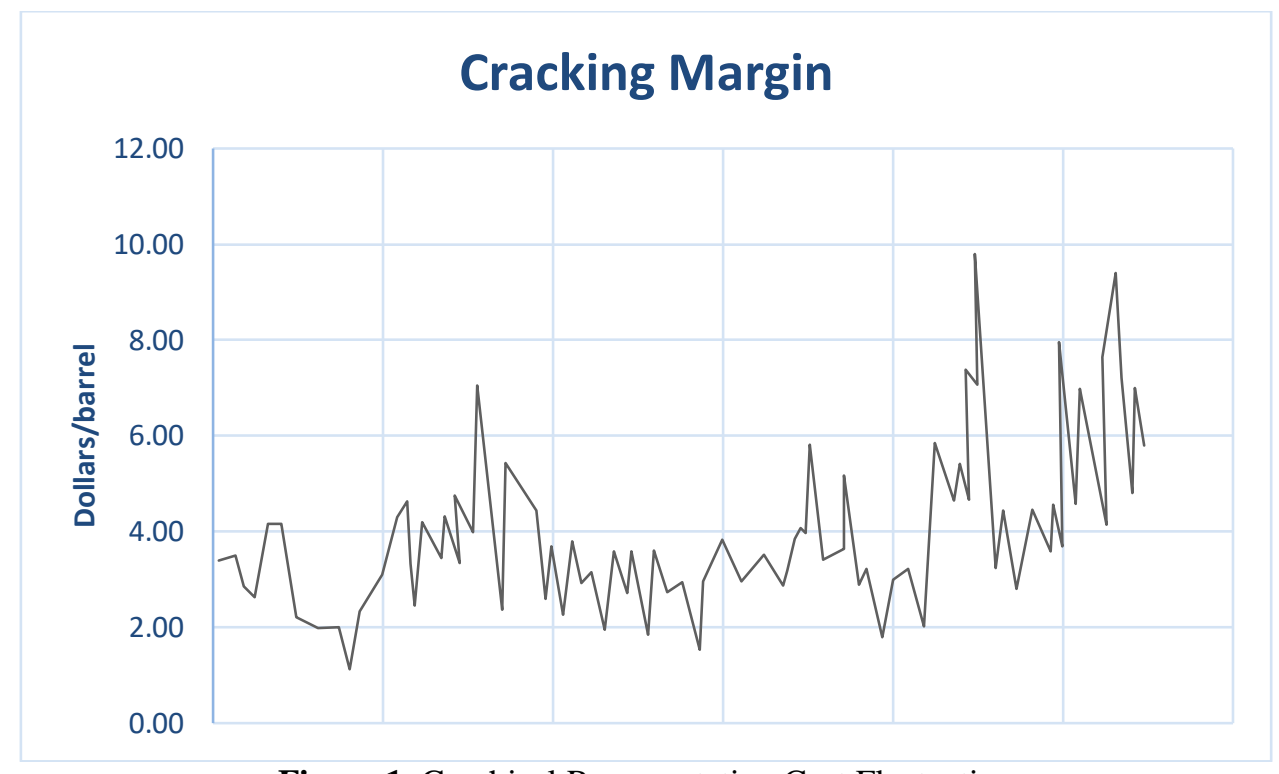

Figure 1. Graphical Representation Cost Fluctuation

\section{Illustration of Problem}

The outline of the problem of integral refinery planning is described in Fig. 2. The aim is to maximize the overall profit achieved during the planning horizon. The problem can be defined as under:

- A set of crude oils.

- A set of crude oil tankers.

- A set of intermediate tanks.

- A set of final product tanks.

- A channel of refineries,

- A channel of interconnection.

- A set of final products.

- A set of depots.

- Pipeline particulars.

- Required data.

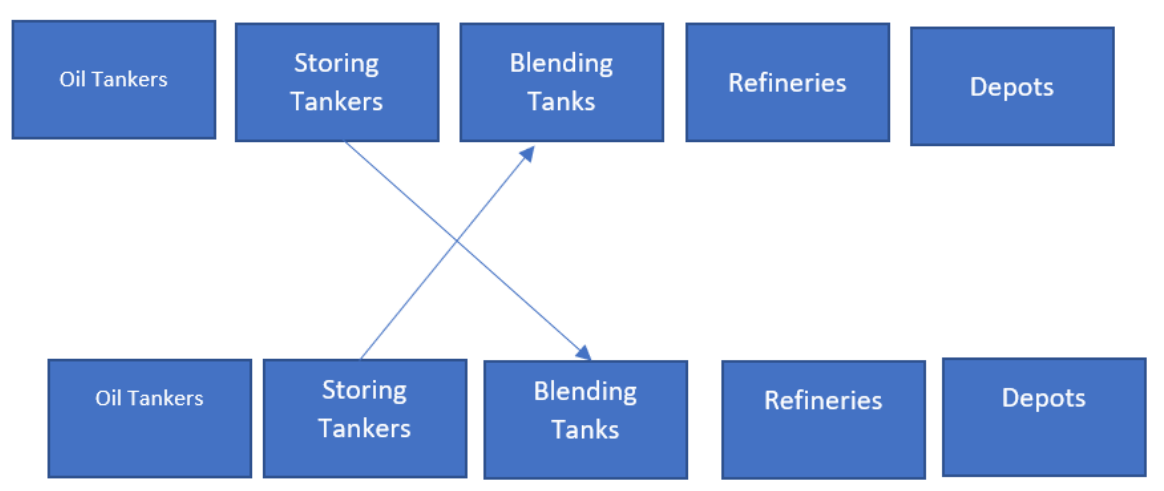

Figure 2. Supply Chain Blocks 


\section{Determine}

- Levels of inventory in each tank,

- Of The rates Material flow among processing units,

- Unit capacity utilization

- Quantity of products to be prepared,

- Income from final product,

- $\quad$ cost of all materials purchased and

- cost of all operations; Subject to:

- Crude supply limitations,

- Refining process issues, and

- Product distribution issues.

Typical refinery has many units and each unit interacts with upstream and down-stream units. Many a time operating all the units at their max capacity may not be beneficial. A typical refinery configuration is shown in Figure 3 below:

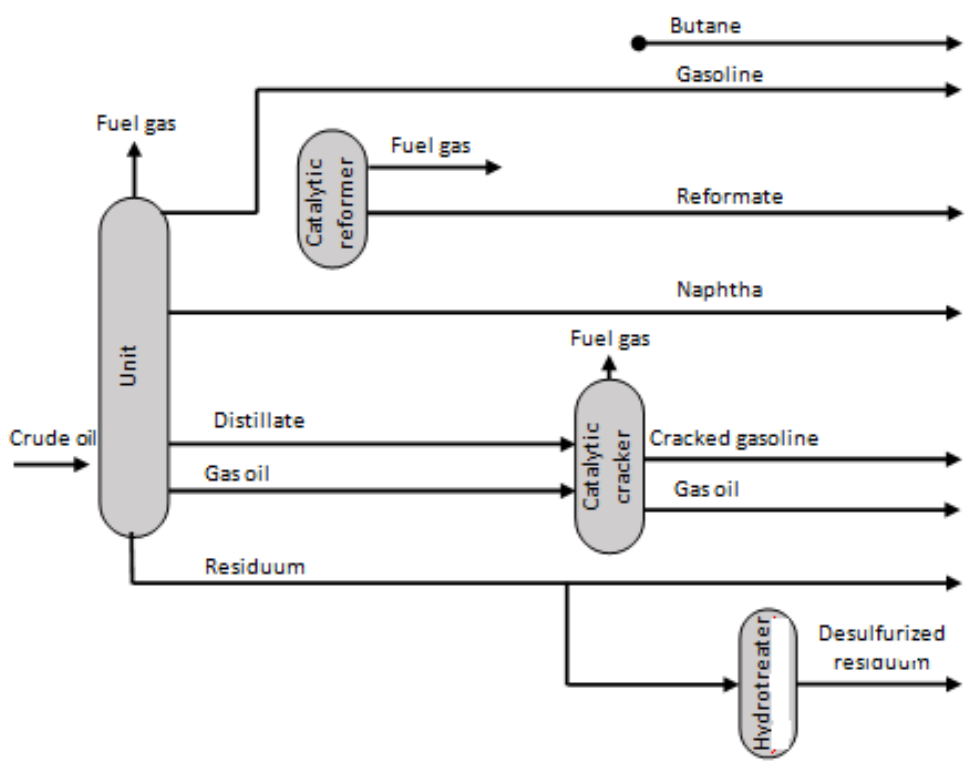

Figure 3. Refinery Framework

KNPC is also one of the typical refineries but it is more complex since the three KNPC refineries are located close by. It has all type of units.

\section{History of Kuwait National Petroleum Company}

"KNPC began in October 1960, in may 1968 the firm established its own "Shuaiba Refinery. Shuaiba Refinery is the world's largest first fuel factory of 195,000 barrels per day of crude production rate. Since 1980, KNPC is operating three oil refineries; Mina Al-Ahmadi, Mina Abdulla and Shuaiba, along with the LPG plant inMina Al-Ahmadi. In 1984 and 1986, the company carried out expansion of the Mina Al-Ahmadi refinery and Further upgrade projects to enhance its capacity to 410,000 barrels/ day. Also completed in 1989 was the Mina Abdulla Refinery Modernization Project, which raised the refinery capacity to 231,000 Barrels/day. KNPC is installing new Projects to improve the quality of petroleum products to meet the new environmental regulations in the global market. In order to remain most efficient and profitable refinery complex KNPC is taking many activities in various business process and increase the value Kuwaiti hydrocarbon. As part of mission KNPC is embarking on Supply chain Optimization project to improve the profitability. Project activities are described in the next section.

\section{Tasks Undertaken}

In an integrated manner, this project explores all related aspects of KNPC systems, concentrating mainly on the following:

Planning processes for the individual and integrated planning and optimization of KNPC refineries, including business process planning, integration with the operation of corporate planning and refineries, and methods and techniques for planning. Specifically, the project focuses on the following two topics: 
Mid-Term operating cycle, which provides direction to short term plans, and covers optimum refinery production plans, market allocations of products and related refining economics.

Short-Term optimization that covers operational optimization in an integrated manner, i.e., refinery production and unit operations, product supply and scheduling, market opportunities, refining economics, etc. Manufacturing and operating systems covering refinery operations, refinery wide simulation for all major process units, inventory projections and management, Multiblend Optimization, scheduling, product supply and distribution.

Performance management systems including oil accounting that provide key indicators, benchmarking, measurement, feedback and corrective actions.

Information technology (IT) infrastructure including data-base management (generation, update, accuracy, control, accessibility, etc.) and effective interface with optimization (LP) models, simulation models and other technical software used for the above areas.

Organizational set-up: Formation of Manufacturing Optimization Group (MOG) covering functions, procedures, responsibility and authority, etc. including role of Short Term Optimization Team (STOT), Corporate Planning department and individual refineries and link with each other in the above areas.

Expertise and training needs as required for meaningful change in the above areas is also included in the scope of the project.

\title{
6. Activities Undertaken
}

This project is expected to take 34 months to complete. The following tools will be used,

\author{
Planning (PIMS) \\ Scheduling (Orion) \\ Global Orion \\ Dock Scheduling \\ Production Accounting (Advisor) \\ Oil Movement (ATOMS) \\ Planning Model Accuracy (PMA) \\ Refinery Modeling (RefSys)
}

These are the major software that will be used for the whole supply chain project. About $30 \%$ of the project and the project has been implemented and is expected to be completed by Dec 2009. We are planning to expand the same to cover the multi-period, with stochastic pricing to later after successful implementations of this project.

\section{References}

7. Crack spread Handbook. New York Mercantile Exchange, 2000.

8. Agrawal, A., \& Balasubramanian, K. (2004). Use an enterprise portal to link plant data with refinery planning tools. Hydrocarbon processing (International ed.), 83(10), 113-117.

9. Kumar, A., Sharma, K., \& Dixit, A.R. (2019). A review of the mechanical and thermal properties of graphene and its hybrid polymer nanocomposites for structural applications. Journal of materials science, 54(8), 59926026.

10. Sharma, K., \& Shukla, M. (2014). Three-phase carbon fiber amine functionalized carbon nanotubes epoxy composite: processing, characterisation, and multiscale modeling. Journal of Nanomaterials, 2014.

11. Sharma, K., Kaushalyayan, K.S., \& Shukla, M. (2015). Pull-out simulations of interfacial properties of amine functionalized multi-walled carbon nanotube epoxy composites. Computational Materials Science, 99, $232-$ 241.

12. Yadav, A., Kumar, A., Singh, P.K., \& Sharma, K. (2018). Glass transition temperature of functionalized graphene epoxy composites using molecular dynamics simulation. Integrated Ferroelectrics, 186(1), $106-$ 114.

13. Singh, P.K., Sharma, K., Kumar, A., \& Shukla, M. (2017). Effects of functionalization on the mechanical properties of multiwalled carbon nanotubes: A molecular dynamics approach. Journal of Composite Materials, 51(5), 671-680.

14. Singh, P.K., \& Sharma, K. (2018). Mechanical and Viscoelastic Properties of In-situ Amine Functionalized Multiple Layer Grpahene/epoxy Nanocomposites. Current Nanoscience, 14(3), 252-262.

15. Singh, P.K., \& Sharma, K. (2018). Molecular Dynamics Simulation of Glass Transition Behaviour of Polymer based Nanocomposites. Journal of Scientific \& Industrial Research, 77(10), 592-595.

16. Kumar, A., Sharma, K., \& Dixit, A.R. (2020). Carbon nanotube-and graphene-reinforced multiphase polymeric composites: review on their properties and applications. Journal of Materials Science, 1-43. 
17. Shukla, M.K., \& Sharma, K. (2019). Effect of carbon nanofillers on the mechanical and interfacial properties of epoxy based nanocomposites: A review. Polymer Science, Series A, 61(4), 439-460.

18. Kumar, A., Sharma, K., \& Dixit, A.R. (2020). A review on the mechanical and thermal properties of graphene and graphene-based polymer nanocomposites: understanding of modelling and MD simulation. Molecular Simulation, 46(2), 136-154

19. Mausam, K., Sharma, K., Bharadwaj, G., \& Singh, R.P. (2019). Multi-objective optimization design of diesinking electric discharge machine (EDM) machining parameter for CNT-reinforced carbon fibre nanocomposite using grey relational analysis. Journal of the Brazilian Society of Mechanical Sciences and Engineering, 41(8), 348.

20. Shukla, M. K., \& Sharma, K. (2019). Improvement in mechanical and thermal properties of epoxy hybrid composites by functionalized graphene and carbon-nanotubes. Materials Research Express, 6(12), 125323.

21. Kumar, K., Sharma, K., Verma, S., \& Upadhyay, N. (2019). Experimental Investigation of Graphene-Paraffin Wax Nanocomposites for Thermal Energy Storage. Materials Today: Proceedings, 18, 5158-5163.

22. Goyal, M. (2018). Shape, size and phonon scattering effect on the thermal conductivity of nanostructures. Pramana, 91(6), 87.

23. Goyal, M., \& Gupta, B.R.K. (2019). Study of shape, size and temperature-dependent elastic properties of nanomaterials. Modern Physics Letters B, 33(26), 1950310.

24. Goyal, M., \& Gupta, B. R. K. (2019). Analysis of shape, size and structure dependent thermodynamic properties of nanowires. High Temperatures--High Pressures, 48(5/6), 481-495.

25. Goyal, M., \& Singh, M. (2020). Size and shape dependence of optical properties of nanostructures. Applied Physics A, 126(3), 1-8.

26. Dhamija, A. (2020). The changing paradigms and evolving dynamics of faith-based tourism in India. International Journal of Scientific and Technology Research, 9(2), 2347-2352.

27. Dhamija, A. (2019). Surviving the COVID-19 menace: A case of higher education sector. International Journal of Psychosocial Rehabilitation, 9(4), 77-86.

28. Dhamija, A. (2019). Adolescent attachment towards passion, intimacy and commitment for spirituality establishment. International Journal of Management and Business Research, 9(4), 77-86.

29. Khan, W., Jamshed, M., Fatima, S., \& Dhamija, A. (2019). Determinants of Income Diversification of Farm Households' in Uttar Pradesh, India. Forum for Social Economics, Routledge, 1-19.

30. Dhamija, A. (2019). Relevance of vedic management in contemporary times. International Journal of Recent Technology and Engineering, 8(2), 3918-3921.

31. Sridhar, P.S.V.S., \& Caytiles, R. (2017). Efficient cloud data hosting availability. Asia-pacific Journal of Convergent Research Interchange, HSST, 11-19.

32. Guleria, M., Rathi, A., Sajwan, D.S., Negi, J.S., \& Chauhan, N. (2017). DTMF Based Irrigation Water Pump Control System. Asia-pacific Journal of Convergent Research Interchange, 3(3), 9-15.

33. Shamim K., Khan, S.A., \& Ahmad, S. (2020). Consumers' understanding of nutrition labels for ultraprocessed food products. Journal of Public Affairs, e2398. 